\title{
Comunicación
}

\section{Aprovechamiento de los residuos blandos de concha de abanico, Argopecten purpuratus (Lamarck, 1819), para producir harina de alto contenido proteico}

\author{
Use of soft waste of the Peruvian scallops Argopecten purpuratus (Lamarck, 1819) \\ to produce high protein meal
Claudio Colán-Ramos ${ }^{1,3,4}$, Muriel Gómez-Sánchez ${ }^{2}$, Juan Arturo Alcazar-Zamora ${ }^{3}$, Arturo Aguirre-Velarde ${ }^{1}$

\section{Resumen}

Los residuos blandos de concha de abanico obtenidos durante su procesamiento son descartados, generando pasivos ambientales a la industria de la maricultura en el Perú. Sin embargo, estos residuos constituyen una potencial materia prima para la elaboración de harina con fines de formulación de alimento balanceado. En este sentido, se desarrolló una metodología para la elaboración de harina a partir de los residuos blandos de la concha de abanico. El producto final obtenido tuvo una composición de $61 \%$ de proteínas, $7.5 \%$ de grasas y $11.7 \%$ de humedad. El desarrollo de tecnologías que permitan el procesamiento de grandes volúmenes de residuos de concha de abanico podría contribuir al uso más eficiente y rentable de esta materia prima.

Palabras clave: Argopecten purpuratus; harina residual; contenido proteico; ácidos grasos; maricultura; residuos orgánicos

\section{Abstract}

The scallop soft waste obtained during processing is discarded, generating environmental liabilities to the mariculture industry in Peru. However, these residues constitute a potential raw material to produce meal for balanced feeds. In this sense, a methodology was developed for the elaboration of meal from the soft residues of the

\footnotetext{
${ }^{1}$ Laboratorio de Ecofisiología Acuática, Instituto del Mar del Perú (IMARPE), Chucuito, Callao, Perú

${ }^{2}$ Organismo Nacional de Sanidad Pesquera (SANIPES), Surquillo, Lima - Perú

${ }^{3}$ Acuicultores Pisco S.A, Lima, Perú

${ }^{4}$ E-mail: claudioadahocr90@gmail.com
}

Recibido: 22 de agosto de 2018

Aceptado para publicación: 21 de marzo de 2019 
Peruvian scallop. The product obtained had a composition of $61 \%$ protein, $7.5 \%$ fat and $11.7 \%$ moisture. The development of technologies that allow the processing of large volumes of waste could contribute to the more efficient and profitable use of this raw material.

Key words: Argopecten purpuratus; residual meal; protein content; fatty acids; mariculture; organic waste

\section{INTRODUCCIÓN}

La harina de pescado es actualmente la principal fuente proteica para la elaboración de alimento balanceado para peces, aves, ganado y otros animales de corral (FAO, 2014). Su alta digestibilidad y su aporte de ácidos grasos poliinsaturados como el omega 3, ácido docosahexaenoico (DHA), ácido eicosapentaenoico (EPA) (Zaldívar et al., 2002) contribuye a potenciar la capacidad reproductora, calidad de gametos y del desarrollo embrionario, así como mejorar las conversiones alimenticias.

La harina de pescado suele ser utilizada en los alimentos para peces en porcentajes que llegan a un $80 \%$ de inclusión (Tacon et al., 2008). Sin embargo, la calidad del insumo, así como la aleatoriedad de la oferta hacen que el precio de la harina de pescado sea variable y frecuentemente elevado. Por otro lado, los stocks de anchoveta, anchoa y sardinas utilizados a nivel mundial para la elaboración de harina de pescado vienen sufriendo una importante presión pesquera, poniéndose en riesgo la sostenibilidad de la producción (FAO, 2014).

La necesidad de contar con insumos alternativos que puedan sustituir la harina de pescado para la elaboración de alimento balanceado, y que además cumplan con el aporte proteico necesario para la alimentación de especies de interés acuícola, ha fomentado la investigación sobre el uso de materias prima de origen vegetal y animal como sustitutos de la harina de pescado (Robaina, 1998).
Si bien el Perú es uno de los mayores productores de harina de pescado a nivel mundial gracias al sistema de afloramiento costero (Guillén y Calienes, 1981; Chávez et al., 2008; Gutiérrez et al., 2011), otros recursos hidrobiológicos como el molusco bivalvo filtrador Argopecten purpuratus (concha de abanico) alcanzan volúmenes de producción importantes. En 2014 se cosecharon $55096 \mathrm{t}$ (PRODUCE, 2014), de los cuales se estima que $10468 \mathrm{t}$ fueron residuos blandos descartados durante el procesamiento (19\%; A. Aguirre, Lima, Comunicación personal). Estos residuos, acumulados en tierra, pueden tener un efecto negativo sobre el ambiente y la población humana expuesta. La generación de fangos y la emisión de olores intensos y persistentes pueden afectar la salud de las poblaciones aledañas (Castells, 2012).

La presente investigación reporta el potencial de los residuos blandos de concha de abanico para ser transformados en harina residual, como alternativa para mitigar los efectos negativos de su vertimiento en el ambiente.

\section{Materiales y Métodos}

\section{Ubicación del Estudio}

El trabajo se llevó a cabo entre marzo y abril de 2017 en las instalaciones del Laboratorio de Ecofisiología Acuática (LEA) perteneciente a la Dirección General de Investigación en Acuicultura (DGIA) del Instituto del Mar del Perú (IMARPE), ubicado en la Punta, Callao, Perú. 


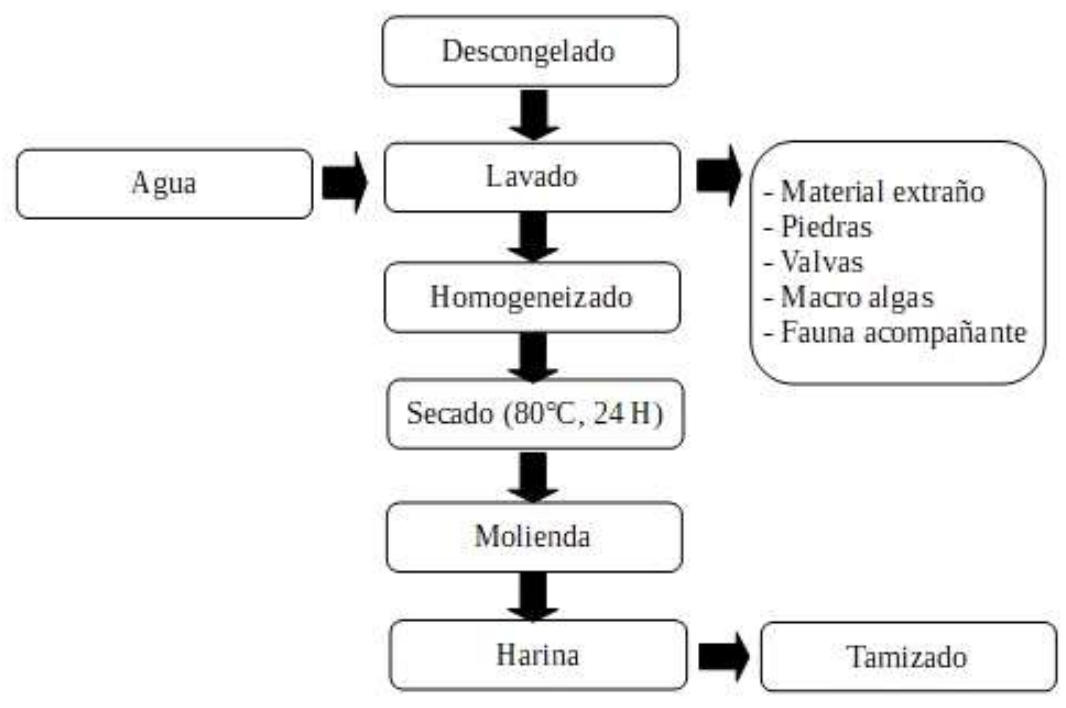

Figura 1.Etapas del proceso de elaboración de harina de residuos de concha de abanico (Argopecten purpuratus).

\section{Materia Prima}

Se colectaron $75 \mathrm{~kg}$ de residuos blandos de concha de abanico de la Bahía de Sechura, Piura, provenientes del proceso de desvalve (proceso primario), para determinar su composición proximal y contenido de ácidos grasos en fresco. Los residuos fueron congelados en paquetes de $1 \mathrm{~kg}$ y trasladados al LEA en cajas de poliestireno expandido. Las muestras estuvieron conformadas por manto, branquias, masa visceral y gónadas. Además, en los residuos se encontraron piedras pequeñas, restos de valvas, macroalgas $\mathrm{y}$ fauna acompañante como ofiuras, gasterópodos y poliquetos, entre otros, presentes durante el cultivo de la concha.

\section{Elaboración de la Harina}

Siete kilogramos de residuos fueron descongelados y lavados con agua dulce, retirándose los restos de valvas, piedras, fauna acompañante, cuerpos extraños y cualquier otro tipo de elemento que pudiera interferir con el proceso. Los residuos fueron escurridos hasta retirar la mayor cantidad de agua posible, asegurando así una masa compacta y evitando promover el desarrollo de bacterias descomponedoras que generarían pérdida del valor nutricional. Los residuos fueron homogeneizados en una moledora de carne, usando un cedazo de 1/8" para obtener partículas de pequeño diámetro, asegurando una adecuada y homogénea una transferencia de calor durante del proceso de secado.

Después del homogeneizado, la masa resultante se colocó en fuentes de papel aluminio. El espesor de la masa sobre la fuente tuvo un máximo de $1 \mathrm{~cm}$. La temperatura de secado fue de $80{ }^{\circ} \mathrm{C}$ durante 36 horas. Por efecto del secado se obtuvo una lámina de color verde-marrón oscuro, la cual fue trozada para ser ingresada a la tolva de un moledor manual para obtener partículas finas entre 250 a $350 \mu \mathrm{m}$. El producto fue tamizado y envasado (Figura 1).

\section{Análisis Proximal y Perfil de Ácidos Grasos}

Las muestras de harina de residuos de concha de abanico fueron analizadas en un laboratorio privado empleando metodologías certificadas para el análisis de productos 
Cuadro 1. Análisis proximal y de ácidos grasos de la harina de residuos blandos de concha de abanico (HRC)

\begin{tabular}{lc}
\hline Análisis & Resultado \\
\hline Calorías (kcl/100g) & 345 \\
Carbohidratos (\%) & 8.09 \\
Cenizas (\%) & 11.03 \\
Fibra (\%) & 0.32 \\
Grasa (\%) & 7.5 \\
Humedad (\%) & 11.7 \\
Proteína (N x 6.25\%) & 61.36 \\
\hline
\end{tabular}

alimentarios. Se determinó el porcentaje nutricional para los siguientes macronutrientes: proteínas (AOAC, 2016a), humedad (NTP - ISO 6496, 2011), cenizas (AOAC, 2016b), grasa (NTP 201.016, 2002), composición de ácidos grasos (ISO 12966-1,2014) y fibra (AOCS, 2009). Finalmente, se calculó la concentración de carbohidratos mediante la diferencia de componentes principales y calorías a partir a partir de la grasa, proteína y carbohidratos.

\section{Resultados y Discusión}

El rendimiento de materia seca (MS) de los residuos de concha abanico fue de $14.29 \%$, lo cual representa una proporción de $7 \mathrm{~kg}$ de MS fresca para obtener $1 \mathrm{~kg}$ de harina (7:1). La concentración de proteína, grasas y cenizas se muestra en el Cuadro 1 .

El contenido proteico se encuentra dentro del rango establecido por la Fundación Española para el Desarrollo de la Nutrición Animal (FEDNA) el cual considera niveles de proteína para cuatro tipos de harina de pescado entre $59-70 \%$ (Cuadro 2). Sin embargo, valores para lípidos (9-9.5\%), cenizas (12.5-21.5\%) y ácidos grasos de cadena larga ( $>20$ carbonos) (3.39-3.76\%) (FEDNA,
2010) superan los valores obtenidos para la harina de concha de abanico (Cuadro 3). Asimismo, la concentración de omega 3 (ácido linolénico, EPA, DHA) fue de $2.28 \mathrm{~g} / 100$ $\mathrm{g}$ muestra y el omega $6 \mathrm{de} 0.31 \mathrm{~g} / 100 \mathrm{~g}$ muestra (Cuadro 3).

Los residuos de concha de abanico empleados no incluyeron las valvas, lo cual se evidencia en la concentración de ceniza obtenida (11.03\%), característica que los hace atractivos, a diferencia de aquellas harinas con altos valores en cenizas, ya que su presencia en una dieta balanceada disminuye la digestibilidad (Romero et al., 1994).

El valor nutricional de los residuos de concha de abanico, al estar constituidos por vísceras y restos de gónadas, son una fuente rica en proteínas y ácidos grasos de alto valor nutricional, al igual que las vísceras y el músculo graso de los peces empleados para la harina de pescado (Sandbol, 1993).

En este sentido, los residuos de concha de abanico poseen potencial como materia prima para elaborar harina residual y posteriormente alimento balanceado. Sin embargo, se deberá diseñar un proceso que permita un procesamiento a mayor escala. Uno de los principales retos es la separación de los residuos sólidos (valvas, fauna acompañante, etc.), los cuales podrían interferir en la calidad de la harina, aumentando la ceniza y sales, generando un efecto negativo sobre la digestibilidad. Asimismo, al igual que la harina de pescado, el desarrollo de una tecnología de elaboración deberá cumplir con los estándares de calidad, evitando la presencia de biotoxinas marinas y la degradación proteica por descomposición (Cruz-Suárez et al., 1998).

\section{Conclusiones}

Los residuos de concha de abanico transformados en harina tienen características nutricionales comparables a la harina de 
Cuadro 2. Valor nutricional de la harina de pescado (descritos en las tablas FEDNA) (De Blas et al., 2010)

\begin{tabular}{lcccccc}
\hline Código & $\begin{array}{c}\text { Proteína } \\
\%\end{array}$ & $\begin{array}{c}\text { Humedad } \\
\%\end{array}$ & $\begin{array}{c}\text { Grasa } \\
\%\end{array}$ & $\begin{array}{c}\text { Fibra } \\
\%\end{array}$ & $\begin{array}{c}\text { Cenizas } \\
\%\end{array}$ & $\begin{array}{c}\text { A.G. }>\text { C20 } \\
\%\end{array}$ \\
\hline Pescado 59/09/21 & 59.0 & 8 & 9.0 & 1 & 21.5 & 3.39 \\
Pescado 62/09/18 & 62.2 & 7.8 & 9.2 & 1 & 18.5 & 3.51 \\
Pescado 67/09/15 & 66.6 & 7.2 & 9.4 & 1 & 15.1 & 3.63 \\
Pescado 70/10/13 & 70.0 & 7.0 & 9.5 & 0.4 & 12.5 & 3.76 \\
\hline
\end{tabular}

Cuadro 3. Ácidos grasos (g/100 g) en la harina de residuos blandos de concha de abanico (HRC)

\begin{tabular}{|c|c|c|}
\hline Ácidos grasos & Código & $\begin{array}{l}\text { Valo } \\
\mathrm{r}\end{array}$ \\
\hline Ácido mirístico & $\mathrm{C} 14: 0$ & 0.57 \\
\hline Ácido palmítico & $\mathrm{C} 16: 0$ & 1.32 \\
\hline Ácido palmitoleico & $\mathrm{C} 16: 1$ & 0.3 \\
\hline Ácido esteárico & $\mathrm{C} 18: 0$ & 0.58 \\
\hline $\begin{array}{l}\text { Ácido linolenico } \\
\text { (omega 3) }\end{array}$ & $\begin{array}{l}\text { C18:3n } \\
3\end{array}$ & 0.26 \\
\hline $\begin{array}{l}\text { Ácido eicosadienoico } \\
\text { (omega 6) }\end{array}$ & $\mathrm{C} 20: 2$ & 0.31 \\
\hline $\begin{array}{l}\text { Ácido } \\
\text { eicosapentanoico } \\
\text { (omega 3) }\end{array}$ & $\begin{array}{l}\text { C20:5 } \\
\text { EPA }\end{array}$ & 1.22 \\
\hline Ácido nervónico & $\mathrm{C} 24: 1$ & 0.2 \\
\hline $\begin{array}{l}\text { Ácido } \\
\text { docosahexanoico } \\
\text { (omega 3) }\end{array}$ & $\begin{array}{l}\text { C22:6 } \\
\text { DHA }\end{array}$ & 0.8 \\
\hline Saturado & & 2.47 \\
\hline Monoinsaturado & & 0.5 \\
\hline Poliinsaturado & & 3 \\
\hline No identificados & & 1.53 \\
\hline
\end{tabular}

pescado. Considerando su condición de residual, posee una composición proximal y un perfil lipídico que le confieren potencial para ser utilizado como insumo en la fabricación de piensos alimenticios.

\section{Agradecimientos}

El presente estudio fue financiado por el proyecto INNOVATE PERÚ, Contrato 283-PNICP-PITEI-2015, de la empresa solicitante Inversiones Pisco S.A. y coejecutado con el Instituto del Mar del Perú (IMARPE), en especial consideración al Laboratorio de Ecofisiología Acuática. Se agradece al PpR 0094 «Ordenamiento y Desarrollo de la Acuicultura» por brindar el marco institucional para la ejecución del trabajo de investigación del presente trabajo.

\section{Literatura Citada}

1. Tacon AG, Metian M. 2008. Global overview on the use of fish meal and fish oil in industrially compounded aquafeeds: trends and future prospects. Aquaculture 285: 146-158. doi: 10.1016/j.aquaculture.2008.08.015

2. [AOAC] Association of Official Analytical Chemists. 2016a. Official methods of analysis. AOAC Official method 984.13. Protein (crude) in animal feed and pet food. Copper Catalyst Kjeldahl Method, $20^{\text {th }}$ ed. Washington DC: AOAC.

3. [AOAC] Association of Official Analytical Chemists. 2016b. Official Methods of Analysis. AOAC Official Method 938.08 Ash of Seafood. Washington, DC: AOAC. [Internet]. 
Available in: http://files.foodmate.com/ 2013/files_2921.html

4. [AOCS] American Oil Chemist Society. 2009. Official methods of analysis and recommended practices of the AOCS. $7^{\text {th }}$ ed. USA: AOCS. $1278 \mathrm{p}$.

5. Castells XE. 2012. Reciclaje de residuos industriales. Residuos sólidos urbanos y fangos de depuradora. Madrid: Díaz de Santos. 1154 p.

6. Chávez FP, Bertrand A, Guevara Carrasco R, Soler P, Csirke. 2008. The Northern Humboldt Current System: brief history, present status and a view towards the future. Prog Oceanogr 79: 95-105. doi: 10.1016/j.pocean.2008.10.012

7. Cruz-Suárez LE, Ricque-Marie D, Nieto-López M, Tapía-Salazar M. 1998. Revisión sobre calidad de harinas y aceites de pescado para la nutrición del camarón. Avances en Nutrición Acuícola IV. En: IV Simposium Internacional de Nutrición Acuícola. La Paz, Bolivia.

8. [FAO] Organización de las Naciones Unidas para la Alimentación y la Agricultura. 2014. El estado mundial de la pesca y la acuicultura. Roma: FAO. [Internet]. Disponible en: http://www.fao.org/resources/infographics/ infographics-details/es/c/232019/. $8 \mathrm{p}$.

9. [FEDNA] Fundación Española para el Desarrollo de la Nutrición Animal. 2010. Tablas FEDNA de composición y valor nutritivo de alimentos para la fabricación de piensos compuestos. $3^{\mathrm{a}} \mathrm{ed}$. Madrid: FEDNA. 502 p.

10. Gutiérrez D, Bouloubassi I, Sifeddine A, Purca S, Goubanova K, Graco M, Field D, et al. 2011. Coastal cooling and increased productivity in the main upwelling zone off Peru since the mid twentieth century. Geophysical Research Letters 38(7): 1-6.
11. [NTP] Norma Técnica Peruana - ISO 6496. 2011. Alimentos para animales. Determinación del contenido de humedad y materia volátil. Lima, Perú.

12. [NTP] Norma Técnica Peruana 201.016. 2002. Carne y productos cárnicos. Determinación del contenido de grasa total. Lima, Perú.

13. ISO 12966-1:2014 Animal and vegetable fats and oils - Gas chromatography of fatty acid methyl esters - Part 2: Preparation of methyl esters of fatty acids, 2014.

14. Guillen O, Calienes R. 1981. Productividad y afloramiento frente a las aguas costeras peruanas. Bol IMARPE Extraordinario: 130-143.

15. [PRODUCE] Ministerio de la Producción. 2014. Anuario estadístico pesquero y acuícola 2014. [Internet] Disponible en: https://www.produce.gob.pe/documentos/estadisticas/anuarios/anuarioestadistico-pesca-2014.pdf

16. Robaina L. 1998. Utilización nutritiva de fuentes de proteína alternativas a la harina de pescado en dietas de engorde para dorada (Sparus aurata). Tesis doctoral. España: Univ. de Las Palmas de Gran Canaria. 213 p.

17. Romero JJ, Castro E, Diaz AM, Reveco M, Zaldivar J. 1994. Evaluation of methods to certify the «premium» quality of Chilean fish meals. Aquaculture 124: 351-358. doi: 10.1016/ 0044-8486(94)90408-1

18. Sandbol P. 1993. Nueva tecnología en la producción de harina de pescado para piensos: implicaciones sobre la evaluación de la calidad. En: IX Curso de Especialización FEDNA. Barcelona, España: FEDNA. 8 p.

19. Zaldívar-Larran FJ. 2002. Las harinas y aceites de pescado en la alimentación acuícola. En: VISimposio Internacional de Nutrición Acuícola. La Paz, Bolivia. 